\title{
Theoretical realities
}

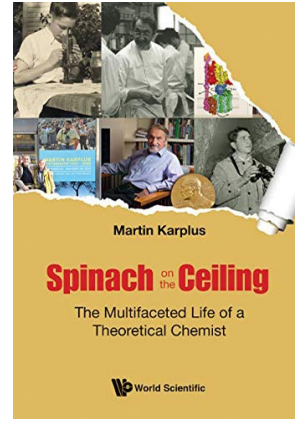

Spinach on the Ceiling: The Multifaceted Life of a Theoretical Chemist

By Martin Karplus

World Scientific Publishing (2020) 350pp, £35.00

$\mathrm{D}$ uring my first semester of college at Johns Hopkins, I spent long hours in the computer lab completing coding assignments. One evening, I noticed a group of students huddled around a screen playing with a vivid, colourful protein structure. The structure in question was that of the Staphylococcus aureus nuclease, the subject of a protein engineering course. I was immediately struck by the aesthetics of protein structures and decided to pursue studies in structural biology shortly thereafter.

Courses on molecular dynamics and a period as a teaching assistant followed, but, despite these experiences, I was unaware of the rich history behind molecular dynamics simulations. Spinach on the Ceiling: The Multifaceted Life of a Theoretical Chemist is an autobiographical work by Martin Karplus, who shared the 2013 Nobel Prize in Chemistry for the development of multiscale models for complex chemical systems. Karplus pioneered molecular dynamics simulations of biomolecules, and his book has drastically revamped my perspective of software that is now routinely run by biophysicists and computational chemists around the world.

Beginning with his childhood adventures birdwatching around New England and examining rotifers under a microscope, Karplus reminds readers of the curiosity and thrill for discovery that drive us all (even if they are frequently clouded by more practical responsibilities such as grant deadlines). He proudly describes how, as a high school senior, he was declared a co-winner of the 1947 Westinghouse Science Talent Search and as a result got to meet US President Harry Truman. Karplus initially planned to study medicine but, like many pre-meds in an era before the existence of combined MD-PhD programmes, decided that research was his true calling. As a freshman, he realized that chemistry and physics are essential to unlock biological mysteries, an idea that underscores the ethos of the molecular dynamics simulations that ultimately made him famous. Discussions with Robert Oppenheimer and Albert Einstein on graduate school plans during his senior year of college are sure to have helped.

Karplus's tales of a turbulent graduate school experience at Caltech will inspire readers to muster fortitude when everything seems to be spinning out of control. He was dismissed by his first advisor after an incident involving Richard Feynman during one of Karplus's seminars. His second advisor abruptly departed for Yale. His research on the properties of bifluoride ions progressed, however, with his third advisor, Linus Pauling. Even then, on completing his thesis, Karplus discovered that a more generalized and elegant approach to his goal had been already published.

Karplus's career is a transatlantic tour de force, detailing fruitful times in Oxford, Illinois, New York City, Cambridge, Paris and Strasbourg. The book walks readers through his early interests in NMR and reaction kinetics that precede the defining moments in the development of the quantum mechanical-molecular mechanical approach and the first molecular dynamics simulation of a biomolecule. Karplus's scientific journey spans more than 70 years and, as such, the details in the book tangibly demonstrate how advances in science and technology go hand-in-hand. As someone who has run molecular dynamics simulations on a petascale supercomputer, I found it fascinating and surreal that Karplus wrote programs during his first faculty position by punching holes in paper tape and filling incorrect holes with nail polish!

While he does not short-change readers interested in biophysics and theoretical chemistry, Karplus balances rigorous scientific discussions with refreshing chapters expounding his passion for photography and gastronomy. He recounts sojourns around the world with his Leica camera and working with curators to hold exhibitions for his photographs (he shares selected images with readers and provides a catalogue of his works in an appendix of the book). A frequent visitor to Michelin three-star restaurants, Karplus chronicles his time donning an apron in kitchens at these establishments to stir beurre blanc, cut veal and slice truffle. Admission to kitchens of this calibre was often challenging - Karplus had to impress Chef Joël Robuchon by identifying in a cream soup a nuanced flavour of sea urchin. Clearly, he came a long way from his "spinach incident" - which inspired the book's title in which he threw a spoonful of spinach at the ceiling as a rambunctious child.

[Karplus'] book has drastically revamped my perspective of software that is now routinely run by biophysicists and computational chemists around the world 5

The book ultimately builds up to Karplus's personal account of winning the 2013 Nobel Prize in Chemistry. His narrative immerses readers in the entire experience of his trip to Stockholm from details as minute as restaurant suggestions from the chauffeur to those as significant as an Einstein-esque defiance regarding the specific contribution being recognized - he strongly believes that his most impactful contribution was developing molecular dynamics simulations for biomolecules. Karplus heartwarmingly concludes the book with stories of the many visits to schools and outreach events as a Nobel laureate, visits that will have inevitably inspired many young scientists to chase their dreams.

Spinach on the Ceiling delivers invaluable insights into the development of molecular dynamics simulations for biomolecules and seamlessly intertwines memorable anecdotes that encapsulate earnest curiosity, steadfast resilience and remarkable work-life balance.

\section{Reviewed by Alfred C. Chin}

Weill Cornell/Rockefeller/Sloan Kettering Tri-Institutional MD-PhD Program, New York, NY, USA

e-mail:acc4002@med.cornell.edu https://doi.org/10.1038/s41570-020-0182-3

\section{Competing interests}

The author declares no competing interests. 